\title{
Bronchoalveolar lavage alterations during prolonged ventilation of patients without acute lung injury
}

\author{
I. Tsangaris*, M.E. Lekka\#, E. Kitsiouli\#, S. Constantopoulos", G. Nakos*
}

Bronchoalveolar lavage alterations during prolonged ventilation of patients without acute lung injury. I. Tsangaris, M.E. Lekka, E. Kitsiouli, S. Constantopoulos, G. Nakos. C ERS Journals Ltd 2003.

ABSTRACT: Mechanical ventilation deteriorates previously injured lung, but little is known about its effect on healthy human lung. This work was designed to assess the effect of prolonged mechanical ventilation on bronchoalveolar lavage (BAL) fluid composition of patients without acute lung injury.

Twenty-two ventilated patients (tidal volume $8-10 \mathrm{~mL} \cdot \mathrm{kg}^{-1}$, positive end-expiratory pressure 3-5 $\mathrm{cmH}_{2} \mathrm{O}$ ) without lung injury, who did not develop any complication from the respiratory system during the 2-week study period, were studied. They were subjected to three consecutive BALs, the first during $36 \mathrm{~h}$ from intubation, the second at the end of the first week of mechanical ventilation and the third at the end of the second week of mechanical ventilation.

Total BAL protein increased during mechanical ventilation $(148 \pm 62,381 \pm 288$, $353 \pm 215 \mu \mathrm{g} \cdot \mathrm{mL}^{-1} \mathrm{BAL}$ for the first, second and third BAL, respectively). In contrast, BAL phospholipids decreased $\left(2.7 \pm 1.1,1.4 \pm 0.6,1.2 \pm 0.7 \mu \mathrm{g} \cdot \mathrm{mL}^{-1} \mathrm{BAL}\right.$, respectively). Large surfactant aggregates were reduced and inflammatory markers, such as platelet activating factor (PAF), PAF-acetylhydrolase and neutrophils, significantly increased after 1 week, but partially remitted after 2 weeks of mechanical ventilation.

In summary, this study demonstrates that prolonged mechanical ventilation even of patients without acute lung injury is associated with the presence of inflammatory markers and surfactant alterations.

Eur Respir J 2003; 21: 495-501.

\author{
*Intensive Care Unit Dept, ${ }^{\top}$ Pulmono- \\ logy Dept, University Hospital of \\ Ioannina, and ${ }^{\#}$ Chemistry Dept, Uni- \\ versity of Ioannina, Ioannina, Greece. \\ Correspondence: G. Nakos, Intensive \\ Care Unit, University Hospital of \\ Ioannina, University Street, 45500 \\ Ioannina, Greece. \\ Fax: 302651099279 \\ E-mail: gnakos@cc.uoi.gr
}

Keywords: Bronchoalveolar lavage, mechanical ventilation, platelet activating factor, surfactant, ventilatorassociated lung injury

Received: May 72002

Accepted after revision: November 12 2002

The work was financially supported in part by the Hellenic Ministry of Development, General Secretariat for Research and Technology, (programme supporting potential researchers 2001).
The harmful effects of mechanical ventilation on lung tissue have been confirmed by a huge amount of experimental data in animal models during the last 15 yrs [1]. The experimental nature of these studies poses great difficulty to the extrapolation of the results to humans, and the demonstration of the alterations or injury, if any, caused by the ventilator to normal human lung presents significant methodological difficulties. Therefore, the clinical study of ventilator-associated lung injury has been limited to patient populations with acute lung injury (ALI). Clinical studies concerning patients with ALI or acute respiratory distress syndrome (ARDS) indicated a deterioration of the injury due to ventilation settings. These results contributed to the development of ventilation strategies that improved the outcome and reduced the rate of complications $[2,3]$. The potential connection of ventilatorassociated lung injury with multiple organ failure [4], a connection not only supported by experimental [5] but by recent clinical data [6], reinforces the need for early detection and reliable monitoring of ventilator-associated lung injury [7].

To prevent the development of ventilator-induced lung injury, it is necessary to elucidate the mechanisms through which ventilation affects the lung. Ventilation strategies can damage the lung by causing the collapse and reopening of the alveoli [8]. One possible mechanism that might lead to lung collapse during expiration is abnormal surfactant composition and function induced by mechanical ventilation [9].

Previous studies have demonstrated significant bronchoalveolar lavage fluid (BALF) alterations in ventilated patients with injured lungs. Such studies have been conducted in ALI/
ARDS [10, 11], pneumonia [12], or cardiogenic lung oedema patients $[12,13]$, and BALF alterations have been attributed to the underlying disease process. BALF is a suitable material to investigate local disorders. It represents alveolar fluid in dilution, containing cells, proteins, enzymes, mediators and lung surfactant. Surfactant contains lipids and proteins and is responsible for stabilising the alveoli, especially in low lung volumes. BALF contains different formations of lung surfactant. These formations include large surfactant aggregates (LSA), which efficiently lower surface tension within the alveolar space, small surfactant aggregates (SSA), and very small surfactant vesicles (VSSA), the latter two of which both have poor surface properties. Surfactant can be fractionated by ultracentrifugation into different subtypes, the heavy in $30,000 \times g$ (LSA), light in the pellet of $100,000 \times g$ (SSA), and ultralight in the supernatant of $100,000 \times g($ VSSA) fractions.

To the authors' knowledge, the issue of BALF alterations due to prolonged mechanical ventilation in patients with "uninjured" lungs has not been addressed. The present study was designed to investigate the alterations in BALF composition observed during prolonged mechanical ventilation in patients with uninjured lungs (according to the Consensus Conference definitions [14]). To achieve this, quantitative and qualitative evaluation of surfactant, protein and inflammatory markers' alterations in BALF were performed in a group of patients without ALI who did not develop any clinically significant respiratory complication during the 2-week study period. 


\section{Materials and methods}

\section{Study subjects}

The Institutional Ethics Committee approved the study and written informed consent was obtained from patients' next of kin. Forty-eight patients requiring mechanical ventilation were initially enrolled in the study in a consecutive series. The inclusion criteria were: arterial oxygen tension $\left(\mathrm{Pa}, \mathrm{O}_{2}\right) /$ inspiratory oxygen fraction $\left(F \mathrm{I}, \mathrm{O}_{2}\right)>39.9 \mathrm{kPa}(300 \mathrm{mmHg})$; no evidence of infiltrate in admission chest radiograph; no history or sign of cardiopulmonary disease; and expected duration for mechanical ventilation exceeding 2 weeks. Patients needing high transfusion volumes or those who developed circulatory shock, bleeding, systemic inflammatory response syndrome, sepsis and any other cause that could induce ALI, either at enrolment or during the course of the study, were excluded. During the 2-week study period, 12 of the patients were diagnosed with ventilator-associated pneumonia (VAP) and eight developed lobar or segmental atelectasis, which required bronchoscopy for resolution. Six patients were excluded for other reasons: four of them died from severe head trauma and two developed massive pulmonary embolism during the first week of the study. Therefore, 22 patients, who did not develop any complication from the respiratory system during the 2-week period, comprised the study group.

VAP was suspected when a new pulmonary infiltrate was evident from chest radiography, combined with compatible clinical signs (purulent tracheal aspirate, rise in body temperature, increase in circulating leukocytes or leukocytes $\leqslant 1,500 \mathrm{~mm}^{-3}$ ), and the diagnosis was confirmed when the quantitative culture of BALF specimen exceeded $1 \times 10^{4}$ colony forming units $\cdot \mathrm{mL}^{-1}$. The diagnosis of atelectasis was made radiologically. Patients were subjected to recruitment manoeuvres and physiotherapy in the usual position and if the atelectasis was not resolved, they were subjected to bronchoscopy.

All patients were ventilated through a cuffed endotracheal tube with a $900 \mathrm{C}$ or 300 Siemens ventilator (Siemens-Elema, Solna, Sweden), using volume control or pressure support mode with a frequency of $10-18 \mathrm{breaths} \cdot \mathrm{min}^{-1}$, tidal volume of $8-10 \mathrm{~mL} \cdot \mathrm{kg}$ body weight ${ }^{-1}$, and positive end-expiratory pressure (PEEP) between $3-5 \mathrm{cmH}_{2} \mathrm{O}$, to minimise the risk of atelectasis. $\mathrm{FI}, \mathrm{O}_{2}$ was set at the minimal level at which an arterial oxygen saturation of $96 \%$ could be achieved. The arterial carbon dioxide tension $\left(\mathrm{Pa}, \mathrm{CO}_{2}\right)$ was kept between $4.0-6.0 \mathrm{kPa}(30-45 \mathrm{mmHg})$. For head-injured patients the initial target for mild hypocapnia was $4.0-4.7 \mathrm{kPa}$ (30$35 \mathrm{mmHg}$ ). The initial resuscitation volume was achieved with crystalloids. A transthoracic echo ensured proper cardiac function during the first $24 \mathrm{~h}$. Demographical characteristics of the 22 patients without complications are shown in table 1 .

\section{Study design}

When the patients fulfilled the inclusion criteria and were haemodynamically stable, the first bronchoalveolar lavage (BAL) was performed. The time interval between intubation and the first BAL was less than $36 \mathrm{~h}$ (mean $16 \mathrm{~h}$, range 6-36 h). Patients were then subjected to BAL at the end of first and second week, in order to have three consecutive BAL procedures with 1-week intervals for every patient who completed the study. Blood gases and lung mechanics were measured just before and $2 \mathrm{~h}$ after the BAL procedure.

Clinical data and characteristics of the first BAL of patients who developed complications from the respiratory system, potentially related to the mechanical ventilation, i.e. VAP (12 patients) and atelectasis (eight patients), were compared with those of patients who did not develop any complication during the study period.
Table 1. -Demographical characteristics of patients without major complications

\begin{tabular}{lccc}
\hline Patient & Age yrs & Sex & Disease \\
\hline 1 & 36 & $\mathrm{~F}$ & $\mathrm{H} / \mathrm{S}$ \\
2 & 61 & $\mathrm{M}$ & $\mathrm{AIS}$ \\
3 & 72 & $\mathrm{M}$ & $\mathrm{TET}$ \\
4 & 50 & $\mathrm{M}$ & $\mathrm{SAH}$ \\
5 & 35 & $\mathrm{M}$ & $\mathrm{H} / \mathrm{S}$ \\
6 & 17 & $\mathrm{M}$ & $\mathrm{H} / \mathrm{S}$ \\
7 & 43 & $\mathrm{M}$ & $\mathrm{NM}$ \\
8 & 71 & $\mathrm{M}$ & $\mathrm{AIS}$ \\
9 & 40 & $\mathrm{M}$ & $\mathrm{H} / \mathrm{S}$ \\
10 & 65 & $\mathrm{M}$ & $\mathrm{SAH}$ \\
11 & 62 & $\mathrm{~F}$ & $\mathrm{TET}$ \\
12 & 39 & $\mathrm{M}$ & $\mathrm{DO}$ \\
13 & 56 & $\mathrm{~F}$ & $\mathrm{SAH}$ \\
14 & 49 & $\mathrm{~F}$ & $\mathrm{SAH}$ \\
15 & 72 & $\mathrm{M}$ & $\mathrm{NM}$ \\
16 & 58 & $\mathrm{M}$ & $\mathrm{SAH}$ \\
17 & 68 & $\mathrm{M}$ & $\mathrm{SAH}$ \\
18 & 24 & $\mathrm{M}$ & $\mathrm{H} / \mathrm{S}$ \\
19 & 34 & $\mathrm{M}$ & $\mathrm{NM}$ \\
20 & 19 & $\mathrm{~F}$ & $\mathrm{H} / \mathrm{S}$ \\
21 & 62 & $\mathrm{M}$ & $\mathrm{SAH}$ \\
22 & 48 & & $\mathrm{SAH}$ \\
Mean & 49.1 & & \\
SD & 16.7 & & \\
\hline
\end{tabular}

M: male; F: female; H/S: head and/or spine trauma; AIS: acute ischaemic stroke; TET: tetanus; SAH: subarachnoid haemorrhage; NM: neuromuscular disease; DO: drug overdose.

\section{Bronchoalveolar lavage procedure}

BAL was performed by fibreoptic bronchoscopy. Patients were ventilated with volume control mode during BAL procedure, $F \mathrm{I}, \mathrm{O}_{2}$ was set at 1.0 and PEEP was removed or reduced. Patients were sedated with midazolam and paralysed with atracurium. Topical anaesthetics were not used. Heart rate, arterial pressure and arterial oxygen saturation by pulse oximetry were monitored throughout the procedure. The trachea was suctioned before introducing the bronchoscope through an adapter (swivel adapter), which allows the maintenance of mechanical ventilation. The tip of the bronchoscope was then wedged in a segmental or subsegmental bronchus of the right middle lobe or the lingula. Left or right lung was randomly selected for the first BAL, the contralateral lung for the second (end of first week), and the initial lung for the third (end of second week), to avoid bronchoscopy induced alterations due to repeated BALs. The mean duration of the bronchoscopy procedure was $6 \pm 2 \mathrm{~min}$.

Six aliquots of $20 \mathrm{~mL}$ sterile normal saline were infused through the working channel of the bronchoscope. The first aspirated fluid, reflecting a bronchial sample, underwent microbiological screening, while the others were collected in ice-cold tubes to avoid platelet activating factor (PAF) degradation due to acetylhydrolases (AcHs) activity. BAL was then filtered through sterile gauze to remove mucus and centrifuged at $500 \times g$, at $4^{\circ} \mathrm{C}$ for $15 \mathrm{~min}$ to obtain the cell pellet. The supernatant of $500 \times g$ was used to measure the biochemical parameters.

\section{Differential centrifugations of bronchoalveolar lavage}

After the removal of cells, an aliquot of the $500 \times g$ supernatant was further centrifuged at $30,000 \times g$, at $4^{\circ} \mathrm{C}$, for $90 \mathrm{~min}$ (Sorvall RC-5B, Dupont, Canada). The pellet of $30,000 \times g$ 
was suspended in a small volume of saline and was kept at $-80^{\circ} \mathrm{C}$ until the analysis of total lipid phosphorus and total proteins was conducted, as described below. The supernatant of $30,000 \times g$ was subjected to ultracentrifugation at $100,000 \times g$, at $4^{\circ} \mathrm{C}$, for $1 \mathrm{~h}$ (Beckman L5-65B with SW41 rotor; Beckman, CA, USA). The pellet and supernatant were kept at $-80^{\circ} \mathrm{C}$ until the analysis. The latter fractions represented the SSA and VSSA, respectively, and the results were used to evaluate the whole separation procedure.

\section{Biochemical parameters in bronchoalveolar lavage}

Total protein and albumin were measured according to previous studies $[15,16]$. Total lipids were extracted from the $500 \times g$ supernatant, according to BLIGH and DYER [17], and separated into classes with thin layer chromatography (TLC), after two successive developments on K-6 thin-layer plates (Whatman; Alltech Associates Inc., Deerfield, IL, USA), in the same direction, using the following solvent systems: 1) chloroformpetroleum:ether:methanol:acetic acid (50:30:15:10, $\mathrm{v} / \mathrm{v}$ ) to the top; and 2) chloroform:methanol:water:acetic acid $(65: 35: 5: 10, \mathrm{v} / \mathrm{v})$ to the top. Phospholipids were visualised under ultraviolet lamp, after spraying with 2-(p-toluidinyl)naphthylene-6-sulphonic acid. Afterwards they were scraped off the plate and measured as described below.

Total phospholipids and individual phospholipid classes after TLC separation were determined from their lipid phosphorus content after $70 \%$ perchloric acid digestion, according to BARTLETT [18].

PAF was purified from the lipid extract of BALF with TLC, using chloroform:methanol:water (65:35:7, v/v). The area between authentic sphingomyelin and lysophosphatidylcholine, where PAF migrates, was scraped off the plate, extracted and tested for biological activity. PAF determination was based on the aggregation of washed rabbit platelets, pretreated with creatine phosphate (CP)/kinase $\mathrm{CP}$, an adenosine diphosphate scavenger, and acetylsalicyliclysine, a cyclooxygenase inhibitor [19]. The standard curve was assessed using the hexadecyl analogue of PAF. The detection limit under these experimental conditions was $40 \mathrm{pg}$ PAF per $9 \mathrm{~mL}$ BALF. Low temperatures were maintained throughout the BAL treatment to avoid PAF degradation due to PAF-AcH hydrolysis. PAF-AcH activity was determined in BALF after trichloroacetic acid precipitation [13].

\section{Bronchoalveolar lavage cells}

BAL cell differential counts were performed by counting at least 300 cells in cytocentrifuge preparations stained with eosin-haematoxylin.

\section{Statistics}

Data are presented as mean \pm SD. Comparisons among the three consecutive BAL results in the study group were performed by one-way analysis of variance (ANOVA) for repeated measures. Comparisons among the study, VAP and atelectasis groups were performed by one-way ANOVA. In both instances, ANOVA was followed by the least significant difference test for post hoc comparisons. Correlations between values were analysed by linear regression. The level of significance was defined as a $\mathrm{p}$-value of $<0.05$.

\section{Results}

\section{Patient data}

Gas exchange, respiratory system mechanics and parameters of mechanical ventilation of study patients are shown in table 2. These values correspond to measurements taken just before each BAL procedure. Blood gases, airway pressures and lung mechanics $2 \mathrm{~h}$ after BAL did not differ from the values before BAL.

Oxygenation $\left(\mathrm{Pa}, \mathrm{O}_{2} / F \mathrm{I}, \mathrm{O}_{2}\right)$ declined after 1 week of mechanical ventilation, which became significant after 2 weeks $(\mathrm{p}<0.05)$. The range of $F \mathrm{I}, \mathrm{O}_{2}$ used to achieve an arterial oxygen saturation exceeding $95 \%$ was between $21-45 \%$, and in none of the cases was an $\mathrm{FI}, \mathrm{O}_{2}$ exceeding 0.5 required.

$P \mathrm{a}, \mathrm{CO}_{2}$ was not altered during the study period. Compliance decreased after 2 weeks of mechanical ventilation $(p<0.05)$. Peak-inspiratory pressure, end-inspiratory (plateau) pressure and PEEP did not change during the study period (table 2).

The volume of BALF recovered from the $120 \mathrm{~mL}$ instilled saline ranged from 54-74\% (mean 63\%). The mean duration of mechanical ventilation was higher in the group of patients who developed VAP compared with those without complications and atelectasis $(\mathrm{p}<0.05)$. Intensive care unit mortality and multiple organ dysfunction syndrome development were not different in the three groups (table 3 ).

\section{Protein content}

Total protein and albumin in the $500 \times g$ supernatant BALF were higher in the second and third BAL compared with the first BAL $(p<0.01)$. There was no difference between the second and third BAL for both total protein and albumin (table 4). The percentage of protein content in the pellet of $30,000 \times g$ was reduced in the second and third BAL compared with the first BAL $(\mathrm{p}<0.05$; table 5$)$. The only correlation found between clinical parameters and BALF characteristics was an inverse relationship between total BAL protein and oxygen tension $/ F \mathrm{I}, \mathrm{O}_{2}$ ratio in the second BAL $\left(\mathrm{r}^{2}=0.45, \mathrm{p}<0.01\right)$.

Table 2. - Clinical characteristics of patients without major complications

\begin{tabular}{|c|c|c|c|c|}
\hline & First BAL & Second BAL & Third BAL & p-value ${ }^{\#}$ \\
\hline$P \mathrm{a}, \mathrm{O}_{2} / F \mathrm{I}, \mathrm{O}_{2} \mathrm{kPa}$ & $47.7 \pm 4.3$ & $44.0 \pm 3.3$ & $41.8 \pm 3.7 *$ & 0.045 \\
\hline $\mathrm{Pa}, \mathrm{CO}_{2} \mathrm{kPa}$ & $4.8 \pm 0.4$ & $5.1 \pm 0.3$ & $5.1 \pm 0.3$ & 0.52 \\
\hline Compliance $\mathrm{mL} \cdot \mathrm{cmH}_{2} \mathrm{O}^{-1}$ & $59 \pm 4$ & $55 \pm 4$ & $49 \pm 5^{*}$ & 0.037 \\
\hline Peak-inspiratory pressure $\mathrm{cmH}_{2} \mathrm{O}$ & $18 \pm 3$ & $20 \pm 3$ & $22 \pm 4$ & 0.28 \\
\hline End-inspiratory pressure $\mathrm{cmH}_{2} \mathrm{O}$ & $14 \pm 3$ & $16 \pm 3$ & $17 \pm 3$ & 0.05 \\
\hline PEEP $\mathrm{cmH}_{2} \mathrm{O}$ & $3 \pm 1$ & $4 \pm 1$ & $4 \pm 1$ & 0.54 \\
\hline
\end{tabular}

Values are presented as mean $\pm \mathrm{SD}$. BAL: bronchoalveolar lavage; $P \mathrm{a}, \mathrm{O}_{2}$ : arterial oxygen tension; $F \mathrm{I}, \mathrm{O}_{2}$ : inspiratory oxygen fraction;

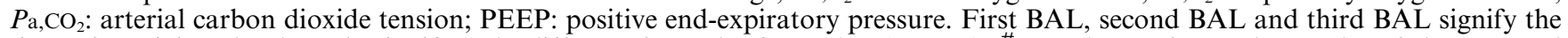
time of receiving the data. *: significantly different from the first BAL $(p<0.05)$; ${ }^{*}$ : $p$-values refer to the results of the repeated measures one-way analysis of variance comparisons among the three consecutive BAL results. 
Table 3.-Initial (first $36 \mathrm{~h}$ ) broncholaveolar lavage (BAL) fluid characteristics and outcome of patients without major complications and patients who later developed ventilator-associated pneumonia (VAP) and atelectasis

\begin{tabular}{|c|c|c|c|c|}
\hline & No complications & VAP & Atelectasis & p-value \\
\hline Total cell count $\times 10^{3}$ & $184 \pm 38$ & $178 \pm 42$ & $186 \pm 35$ & 0.14 \\
\hline Alveolar macrophage $\%$ & $83 \pm 9$ & $83 \pm 7$ & $85 \pm 6$ & 0.53 \\
\hline Neutrophils $\%$ & $11 \pm 5$ & $14 \pm 5$ & $12 \pm 4$ & 0.055 \\
\hline Total protein $\mu \mathrm{g} \cdot \mathrm{mL}^{-1}$ & $148 \pm 62$ & $177 \pm 58$ & $166 \pm 53$ & 0.12 \\
\hline Albumin $\mu \mathrm{g} \cdot \mathrm{mL}^{-1}$ & $40 \pm 19$ & $55 \pm 17$ & $56 \pm 18$ & 0.28 \\
\hline $\mathrm{PAF} \mathrm{pg} \cdot \mathrm{mL}^{-1} \mathrm{BAL}$ & $1 \pm 3$ & 0 & 0 & 0.51 \\
\hline $\mathrm{PAF}-\mathrm{AcH}$ nmol PAF $\cdot \mathrm{mL}^{-1} \mathrm{BAL} \cdot \mathrm{min}^{-1}$ & $0.05 \pm 0.02$ & $0.06 \pm 0.03$ & $0.06 \pm 0.03$ & 0.52 \\
\hline Total PL $\mu \mathrm{g} \cdot \mathrm{mL}^{-1}$ BAL & $2.7 \pm 1.1$ & $2.6 \pm 0.8$ & $2.8 \pm 0.9$ & 0.87 \\
\hline PC $\%$ of total PL & $71 \pm 5$ & $70 \pm 12$ & $68 \pm 12$ & 0.76 \\
\hline PG $\%$ of total PL & $10 \pm 3$ & $9 \pm 2$ & $8 \pm 2$ & 0.74 \\
\hline SM $\%$ of total PL & $6 \pm 1$ & $5 \pm 1$ & $6 \pm 2$ & 0.84 \\
\hline $\mathrm{PE} \%$ of total PL & $4 \pm 1$ & $4 \pm 1$ & $4 \pm 1$ & 0.48 \\
\hline $\mathrm{PS} \%$ of total PL & $4 \pm 2$ & $5 \pm 1$ & $5 \pm 2$ & 0.75 \\
\hline PI $\%$ of total PL & $5 \pm 2$ & $5 \pm 1$ & $5 \pm 1$ & 0.62 \\
\hline Lyso-phosphatidylcholine \% of total PL & 0 & 0 & 0 & 0.8 \\
\hline Died n $(\%)$ & $6(27 \%)$ & $5(41 \%)$ & $3(37 \%)$ & 0.08 \\
\hline MV days & $19 \pm 5$ & $27 \pm 8 *$ & $17 \pm 5$ & 0.042 \\
\hline MODS n $(\%)$ & $4(18 \%)$ & $4(33 \%)$ & $2(25 \%)$ & 0.09 \\
\hline
\end{tabular}

Values are presented as mean \pm SD unless otherwise stated. PAF: platelet activating factor; AcH: acetylhydrolase; PL: phospholipid; PC: phosphatidylcholine; PG: phosphatidylglycerol; SM: sphingomyelin; PE: phosphatidylenthanolamine; PS: phosphatidylserine; PI: phosphatidylinositol; MV: mechanical ventilation; MODS: multiple organ dysfunction syndrome. *: significantly different from patients without complications and those with atelectasis $(\mathrm{p}<0.05)$; ${ }^{\text {: }}$ p-values refer to the result of the one-way analysis of variance comparisons among the three groups.

\section{Surfactant phospholipids}

The total phospholipid content of the $500 \times g$ supernatant BALF was reduced in the second BAL compared with the first $(\mathrm{p}<0.001)$. There was no difference between the second and third BAL (table 4). The percentage of the total phospholipids in the pellet of $30,000 \times g$, which represents LSA, was reduced, while it increased in the VSSA isolated from the second and third BAL compared with the first BAL $(\mathrm{p}<0.05$ and $\mathrm{p}<0.01$, respectively; table 5).

A qualitative deficiency of surfactant phospholipids was also observed. The percentage of phosphatidylcholine (PC) and phosphatidylglycerol (PG) decreased, while sphingomyelin
(SM), phosphatidylethanolamine, phosphatidylserine, and phosphatidylinositol (PI) increased in the second and third compared with the first BAL (table 4). Lyso-phosphatidylcholine was detected only in the second BAL. No qualitative differences of surfactant phospholipids between the second and third BAL were observed.

Platelet activating factor and platelet activating factoracetylhydrolase

PAF was increased in the second and third BALF compared with the first $(\mathrm{p}<0.001)$ where it was actually not

Table 4.-Bronchoalveolar lavage (BAL) fluid characteristics of patients without major complications

\begin{tabular}{|c|c|c|c|c|}
\hline & First BAL & Second BAL & Third BAL & p-value \\
\hline Total cell count $\times 10^{3}$ & $184 \pm 38$ & $195 \pm 43$ & $189 \pm 55$ & 0.66 \\
\hline Alveolar macrophage $\%$ & $83 \pm 9$ & $71 \pm 11 *$ & $77 \pm 16$ & 0.033 \\
\hline Neutrophils $\%$ & $11 \pm 5$ & $22 \pm 9 *$ & $15 \pm 7$ & 0.008 \\
\hline Total protein $\mu \mathrm{g} \cdot \mathrm{mL}^{-1}$ & $148 \pm 62$ & $381 \pm 288^{*}$ & $353 \pm 215^{*}$ & 0.00077 \\
\hline Albumin $\mu \mathrm{g} \cdot \mathrm{mL}^{-1}$ & $40 \pm 19$ & $131 \pm 95^{*}$ & $118 \pm 67 *$ & $<0.0001$ \\
\hline Albumin/total protein $\%$ & 28 & 34 & 33 & 0.12 \\
\hline $\mathrm{PAF} \mathrm{pg} \cdot \mathrm{mL}^{-1} \mathrm{BAL}$ & $1 \pm 3$ & $93 \pm 115^{*}$ & $33 \pm 39 *$ & $<0.0001$ \\
\hline $\mathrm{PAF}-\mathrm{AcH} \mathrm{nmol} \mathrm{PAF} \cdot \mathrm{mL}^{-1} \mathrm{BAL} \cdot \mathrm{min}^{-1}$ & $0.05 \pm 0.02$ & $0.56 \pm 0.15^{*}$ & $0.13 \pm 0.06^{*}$ & $<0.0001$ \\
\hline Total PL $\mu \mathrm{g} \cdot \mathrm{mL}^{-1} \mathrm{BAL}$ & $2.7 \pm 1.1$ & $1.4 \pm 0.6^{*}$ & $1.2 \pm 0.7^{*, \#}$ & $<0.0001$ \\
\hline $\mathrm{PC} \%$ of total PL & $71 \pm 5$ & $56 \pm 6^{*}$ & $60 \pm 8^{*}, \#$ & $<0.0001$ \\
\hline PG $\%$ of total PL & $10 \pm 3$ & $6 \pm 1 *$ & $6 \pm 2 *$ & $<0.0001$ \\
\hline $\mathrm{SM} \%$ of total PL & $6 \pm 1$ & $17 \pm 3^{*}$ & $16 \pm 4^{*}$ & $<0.0001$ \\
\hline $\mathrm{PE} \%$ of total PL & $4 \pm 1$ & $6 \pm 2 *$ & $5 \pm 1^{\#}$ & 0.0007 \\
\hline PS $\%$ of total PL & $4 \pm 2$ & $6 \pm 1 *$ & $6 \pm 1 *$ & 0.002 \\
\hline PI $\%$ of total PL & $5 \pm 2$ & $7 \pm 2 *$ & $7 \pm 2 *$ & 0.008 \\
\hline Lyso-phosphatidylcholine \% of total PL & 0 & $2 \pm 1$ & 0 & $<0.0001$ \\
\hline
\end{tabular}

Values are presented as mean \pm SD. PAF: platelet activating factor; AcH: acetylhydrolase; PL: phospholipids; PC: phosphatidylcholine; PG: phosphatidylglycerol; SM: sphingomyelin; PE: phosphatidylethanolamine; PS: phosphatidylserine; PI: phosphatidylinositol. First BAL, second BAL and third BAL signify the time of receiving the data. *: significantly different from first BAL ( $<<0.05$ ); \#. significantly different from second BAL $(\mathrm{p}<0.05)$; ${ }^{\uparrow}$ : $\mathrm{p}$-values refer to the result of the repeated measures one-way analysis of variance comparisons among the three consecutive BAL results. 
Table 5. - Differential centrifugations of bronchoalveolar lavage (BAL) fluid

\begin{tabular}{|c|c|c|c|c|}
\hline & First BAL & Second BAL & Third BAL & p-value ${ }^{\#}$ \\
\hline \multicolumn{5}{|l|}{ Protein $\%$ of total } \\
\hline Pellet $30000 \times g$ & $17.2 \pm 3.3$ & $11.2 \pm 2.2 *$ & $10.1 \pm 2.4^{*}$ & 0.006 \\
\hline Pellet $100000 \times g$ & $8.1 \pm 1.3$ & $7.2 \pm 1.1$ & $8 \pm 2.6$ & 0.43 \\
\hline Supernatant $100000 \times g$ & $74.3 \pm 12.5$ & $80.7 \pm 15.3$ & $79.3 \pm 12.8$ & 0.09 \\
\hline \multicolumn{5}{|l|}{ Lipids $\%$ of total } \\
\hline Pellet $30000 \times g$ & $85.1 \pm 13.4$ & $66 \pm 14.2 *$ & $63 \pm 12.2 *$ & 0.007 \\
\hline Pellet $100000 \times g$ & $9.5 \pm 1.8$ & $8.9 \pm 2.1$ & $9.4 \pm 1.8$ & 0.67 \\
\hline Supernatant $100000 \times g$ & $5.7 \pm 1.1$ & $23.4 \pm 6.5^{*}$ & $25.2 \pm 7.7^{*}$ & $<0.0001$ \\
\hline
\end{tabular}

Values are presented as mean $\pm \mathrm{SD}$. *: significantly different from first $\mathrm{BAL}(\mathrm{p}<0.05)$; ${ }^{*}: \mathrm{p}$-values refer to the result of the repeated measures one-way analysis of variance comparisons among the three consecutive BAL results.

detectable. PAF was reduced in the third BAL in comparison with the second $(\mathrm{p}<0.005)$.

PAF-AcH was increased in the second BALF compared with the first $(p<0.001)$ and was reduced in the third BAL $(\mathrm{p}<0.01)$, however, it remained significantly higher in comparison with the first BALF $(\mathrm{p}<0.01$; table 4$)$.

\section{Cells}

Total BAL cell counts were not altered between BAL procedures. The percentage of neutrophils increased in the second BAL $(\mathrm{p}<0.01)$. In the third BAL, the cells showed a tendency to return to the initial state (table 4).

\section{Patients with ventilator-associated pneumonia and atelectasis}

The initial values of gas exchange, respiratory system mechanics, and BALF characteristics (table 3) among the patients without any major complication and those who developed VAP and atelectasis did not show any difference. In addition, no differences were detected among these three groups in age, severity of disease, use of antibiotics prior to VAP, sedation and paralysis administration, position, nutrition and gastroprophylaxis.

\section{Discussion}

Considerable alterations in BALF were demonstrated during mechanical ventilation of patients who did not develop any complication from the respiratory system. An increase in total protein and albumin content was observed. Surfactant abnormalities were manifested as a decrease in total phospholipid content, abnormal phospholipid profile and reduced proportion of LSA. Finally, increased levels of inflammatory markers, such as PAF and neutrophils, emerged.

\section{Protein content}

BALF protein increased after 1 week of mechanical ventilation compared with the initial values. The level of protein also remained high during the second week. Several possibilities must be considered as possible explanations for this finding, such as an increase of permeability of capillary/ alveolar membrane, an increase of protein contamination of alveolar fluid due to local inflammation, or condensation due to removal of alveolar fluid [20, 21]. Since no reliable alveolar fluid volume markers exist, it is impossible to differentiate between the above or to determine the degree of contribution from each of them.

Mechanical ventilation has been shown to induce interstitial and alveolar oedema in experimental models and altered permeability, resulting in increased protein in BALF [1]. Surfactant abnormalities have been considered as contributing factors to ventilator-induced pulmonary oedema in animal models [22-24]. Besides this, it is well established that the presence of alveolar fluid, along with increased concentration of protein, especially albumin, inactivates surfactant and influences its biophysical properties [25]. The patients in this study exhibited a significant rise in total protein and albumin accompanied by surfactant reduction during mechanical ventilation. The inhibitory effect of proteins may further deteriorate the already poor surface activity due to low concentration and qualitative surfactant alterations.

\section{Lipid alterations}

Total phospholipid content was found to decline with time and the decline was evident in all patients. This finding could be attributed either to a reduced secretion/production and might reflect an injury of type-II alveolar cells [26], or even to an increased surfactant secretion in the first BAL, due to initiation of harmful mechanical ventilation. This latter interpretation is consistent with previous results referring to BAL alterations in patients during the course of ARDS, where total phospholipids appeared increased in the early phase compared with the late phase [11]. Increased surfactant concentration has been also observed in BALF of animal models after a short period of mechanical ventilation with high tidal volume and low PEEP [27]. Surfactant secretion is a complex process controlled by different interdependent pathways, among which hyperventilation seems to play a major prosecretory role [28]. Phospholipid content increases with lung overdistension [29] and it has been demonstrated that even a single deep breath can induce a transient oversecretion [30]. Total phospholipids have been found to be low in mechanically ventilated patients with ARDS [9-11], pneumonia [12], or cardiogenic lung oedema $[12,13]$. This decrease has been ascribed mainly to the underlying lung disease. The possible contribution of other factors, such as alterations due to prolonged mechanical ventilation, has been overlooked.

The main phospholipid profile changes in this study were a decrease in PC and PG and an increase in SM and PI. Since the main function of $\mathrm{PC}$ is to reduce surface tension at the air/ liquid interface of the alveolar spaces, the significant decrease of PC could lead to increased surface activity [26]. The change in the percentage of the two acidic phospholipids PG and PI, which was demonstrated in this set of patients, has also been observed in experimental animals with alveolar injury $[26,31]$ and could reflect an injury of type-II alveolar cells. 
Besides the qualitative and quantitative phospholipid alterations, a reduced proportion of LSA was observed during the second and third BAL. The ratio of inactive to active surfactant has been proposed as one of the earliest markers of lung injury in a septic adult sheep model [32]. The predominance of the very small aggregate forms has been associated with impaired surface properties and deterioration of lung function [33]. The present results agree with reports indicating that the ratio of SSA to LSA was higher in injured lung and was correlated with an increase in surface tension [34]. Although surfactant abnormalities are risk factors for VAP and atelectasis [26], it was not possible to predict the development of such disorders from the initial BAL characteristics.

\section{Inflammatory markers}

PAF is a highly potent lipid mediator implicated in local inflammatory mechanisms and its levels have been used as a marker of ventilator-induced lung injury in animal models [35]. In this group of patients, high levels of PAF were detected in BALF after 1 week of mechanical ventilation, while, during the second week, a remission was observed. The proportion of BAL neutrophils showed the same variation. The presence of PAF and increased neutrophils in BALF implies the development of a local inflammatory reaction. During the course of the study, these patients did not exhibit any recognised respiratory complication, which could explain this disorder, and, besides, there were no clinical or laboratory signs compatible with a systemic inflammatory reaction. Therefore, the application of mechanical ventilation, or even possible subclinical disorders, such as micro-atelectasis, could be regarded as causative factors. The reason for the reduction in all the inflammatory markers during the second week is not well understood, but it is possible an anti-inflammatory response might play a role in this phenomenon.

It has been shown that mechanical ventilation caused liberation of inflammatory and anti-inflammatory mediators in the alveoli of animals, and this was evident (although to a different extent) with every mode of ventilation used [36]. These data suggest that a mechanical factor (mechanical ventilation) can initiate a number of cellular responses leading to lung injury. Manipulating pressure or volume setting in the ventilator could, at least partially, prevent the ventilatorinduced lung injury $[6,36]$. However, other investigators seem to question it [37, 38]. RICARD and DREYFuss [38] found increased macrophage inflammatory protein (MIP)-2 production in BALF of animals after harmful and unharmful mechanical ventilation. However, they did not observe any release of tumour necrosis factor- $\alpha$ or interleukin-1 $\beta$. The present results (i.e. increased PAF) are in accordance with those of the former investigators who found increased inflammatory mediators. Nevertheless, the increase of MIP-2, which is a chemotactic factor for neutrophils, is not in contrast with the authors' results, where BAL neutrophils increased during the mechanical ventilation, since the increase of MIP-2 was observed even with low tidal volume mechanical ventilation.

\section{Clinical implication}

It is noteworthy that the alterations observed in the present study appeared while using moderate tidal volumes and necessary PEEP, while end-inspiratory pressures were considered nontraumatic for the alveolar epithelium. In fact, the end-inspiratory pressures were consistently lower than $20 \mathrm{cmH}_{2} \mathrm{O}$ and the range of tidal volumes used is considered safe for the noninjured lung. During the observation period, the compliance, as well as arterial oxygenation, exhibited a mild declining tendency with time. These subtle changes in oxygenation and compliance are often overlooked in routine clinical practice, since they do not require any intervention or further measurement. A prevention of these disorders with a specific ventilation strategy or other therapeutic approach could be potentially beneficial to the patient. However, this group of patients did not experience major complications despite lung surfactant abnormalities.

Surfactant alterations, as well as the presence of inflammatory markers in BALF, found in the present study, are considered risk factors for developing VAP, atelectasis, and barotrauma $[8,26]$. However, this study was not designed to answer the question of whether the abnormalities observed in BALF could eventually lead to VAP, atelectasis, or barotrauma. Moreover, the design of the present study could not exclude the potential confounding effect of "subclinical" situations, such as microaspirations, emboli, or oxygen toxicity on BALF alterations. Indeed, an ideal control group for this study would be intubated patients breathing spontaneously, without the need of using mechanical ventilation, but such patients are quite infrequently available for the 2-week protocol of this study.

To conclude, this study demonstrates that prolonged mechanical ventilation even of patients with "uninjured" lungs is associated with the presence of inflammatory markers in bronchoalveolar lavage fluid and surfactant alterations. The clinical impact and importance of these alterations are unknown and the subject needs further investigation.

\footnotetext{
Acknowledgements. The authors would like to thank A. Katsaraki for statistical support.
}

\section{References}

1. Dreyfuss D, Saumon G. Ventilator-induced lung injury: Lessons from experimental studies. Am J Respir Crit Care Med 1998; 157: 294-323.

2. Amato MB, Barbas CS, Medeiros DM, et al. Effect of a protective-ventilation strategy on mortality in the acute respiratory distress syndrome. $N$ Engl J Med 1998; 338: $347-354$.

3. The Acute Respiratory Distress Syndrome Network. Ventilation with lower tidal volumes as compared with traditional tidal volumes for acute lung injury and the acute respiratory distress syndrome. N Engl J Med 2000; 342: 1301-1318.

4. Slutsky AS, Tremblay LN. Multiple system organ failure: is mechanical ventilation a contributing factor? Am J Respir Crit Care Med 1998; 157: 1721-1725.

5. Chiumello D, Pristine G, Slutsky AS. Mechanical ventilation affects local and systemic cytokines in an animal model of acute respiratory distress syndrome. Am J Respir Crit Care Med 1999; 160: 109-116.

6. Ranieri VM, Suter PM, Tortorella C, et al. Effect of mechanical ventilation on inflammatory mediators in patients with acute respiratory distress syndrome: a randomized controlled trial. JAMA 1999; 282: 54-61.

7. International Consensus Conferences in Intensive Care Medicine. Ventilator-associated lung injury in ARDS. Am J Respir Crit Care Med 1999; 160: 2118-2124.

8. Dos Santos CC, Slutsky AS. Cellular responses to mechanical stress. Invited review. Mechanisms of ventilator-induced lung injury: a perspective. J Appl Physiol 2000; 89: 1645-1655.

9. Verbrugge SJ, Bohm SH, Gommers D, Zimmerman LJ, Lachmann B. Surfactant impairment after mechanical ventilation with large alveolar surface area changes and effects of positive end-expiratory pressure. $\mathrm{Br} J$ Anaesth 1988; 80: 360-364.

10. Pison U, Seeger W, Buchhorn R, et al. Surfactant 
abnormalities in patients with respiratory failure after multiple trauma. Am Rev Respir Dis 1989; 140: 1033-1039.

11. Nakos G, Kitsiouli E, Tsangaris H, Lekka ME. Bronchoalveolar lavage fluid characteristics of early, intermediate and late phase of ARDS: Alterations in leukocytes, proteins, PAF and surfactant components. Intensive Care Med 1998; 24: 296-303.

12. Guenther A, Siebert C, Schmidt R, et al. Surfactant alterations in severe pneumonia, acute respiratory distress syndrome, and cardiogenic lung edema. Am J Respir Crit Care Med 1996; 153: 176-184.

13. Nakos G, Pneumaticos J, Tsangaris I, Tellis C, Lekka M. Proteins and phospholipids in BAL from patients with hydrostatic pulmonary edema. Am J Respir Crit Care Med 1997; 155: 945-951.

14. Artigas A, Bernard GR, Carlet J, et al. The AmericanEuropean Consensus Conference on ARDS, part 2: Ventilatory, pharmacologic, supportive therapy, study design strategies, and issues related to recovery and remodeling. Acute respiratory distress syndrome. Am J Respir Crit Care Med 1998; 157: 1332-1347.

15. Lowry OH, Rosebrough NJ, Farr AL, Randall RJ. Protein measurement with the Folin phenol reagent. $J$ Biol Chem 1951; 193: 265-275.

16. Doumas BT, Biggs HG. Determination of serum albumin. In: Cooper GA, ed. Standard Methods of Clinical Chemistry. Volume 7. New York, Academic Press, 1972; pp. 175-189.

17. Bligh EG, Dyer WJ. A rapid method of total lipid extraction and purification. Can J Biochem Physiol 1959; 37: 911-917.

18. Bartlett GR. Phosphorus assay in column chromatography. J Biol Chem 1959; 234: 466-468.

19. Bossant MJ, Ninio E, Delautier D, Benveniste J. Bioassay of paf-acether by rabbit platelet aggregation. In: Murphy RC, Fitzpatrick FA, eds. Methods Enzymology. Volume 187. San Diego, Academic Press, 1990; pp. 125-130.

20. Matthay MA, Wiener-Kronish JP. Intact epithelial barrier function is critical for the resolution of alveolar edema in humans. Am Rev Respir Dis 1990; 142: 1250-1257.

21. Matthay MA, Landolt CC, Staub NC. Differential liquid and protein clearance from alveoli in anesthetized sheep. J Appl Physiol 1982; 53: 96-104.

22. Jefferies AL, Kawano T, Mori S, Burger R. Effect of increased surface tension and assisted ventilation on $99 \mathrm{~m}$ Tc-DTPA clearance. J Appl Physiol 1988; 64: 562-568.

23. Nieman G, Ritter-Hrncirik C, Grossman Z, Witanowski L, Clark W Jr, Bredenberg C. High alveolar surface tension increases clearance of technetium $99 \mathrm{~m}$ diethylenetriaminepentaacetic acid. J Thorac Cardiovasc Surg 1990; 100: 129-133.

24. Albert RK, Lakshminarayan S, Hildenbrandt J, Kirk W,
Butler J. Increased surface tension favors pulmonary edema formation in anesthetized dogs' lungs. J Clin Invest 1979; 63 : $1015-1018$.

25. Holm BA, Enhorning G, Notter RH. A biophysical mechanism by which plasma proteins inhibit lung surfactant activity. Chem Phys Lipids 1988; 38: 287-298.

26. Griese M. Pulmonary surfactant in health and human lung diseases: state of the art. Eur Respir J 1999; 13: 1455-1476.

27. Veldhuizen RAW, Marcou J, Yao LJ, McCaig L, Ito Y, Lewis JF. Alveolar surfactant aggregate conversion in ventilated normal and injured rabbits. Am J Physiol 1996; 14: L152-L158.

28. Mason RJ, Voelker DR. Regulatory mechanisms of surfactant secretion. Biochim Biophys Acta 1998; 1408: 226-240.

29. Faridy EE. Effect of distension on release of surfactant in excised dogs' lungs. Respir Physiol 1976; 27: 99-114.

30. Nicholas TE, Power JH, Barr HA. The pulmonary consequences of a deep breath. Respir Physiol 1982; 49: 315-324.

31. Adachi H, Hayashi H, Sato H, Dempo K, Akino $\mathrm{T}$ Characterization of phospholipids accumulated in pulmonarysurfactant compartments of rats intratracheally exposed to silica. Biochem J 1989; 262: 781-786.

32. Lewis JF, Veldhuizen R, Possmayer F, et al. Altered alveolar surfactant is an early marker of acute lung injury in septic adult sheep. Am J Respir Crit Care Med 1994; 150: 123-130.

33. Veldhuizen RAW, Ito Y, Marcou J, Yao LJ, McCaig L, Lewis JF. Effects of lung injury on pulmonary surfactant aggregate conversion in vivo and in vitro. Am J Physiol 1997; 16: L872-L878.

34. Ueda T, Ikegami M, Jobe A. Surfactant subtypes: In vitro conversion, in vivo function, and effects of serum proteins. Am J Respir Crit Care Med 1994; 149: 1254-1259.

35. Imai $\mathrm{Y}$, Kawano $\mathrm{T}$, Miyasaka $\mathrm{K}$, Takata $\mathrm{M}$, Imai $\mathrm{T}$, Okuyama K. Inflammatory chemical mediators during conventional ventilation and during high frequency oscillatory ventilation. Am J Respir Crit Care Med 1994; 150: $1550-1554$.

36. Tremblay LN, Valenza F, Ribeiro SP, Li J, Slutsky AS. Injurious ventilatory strategies increase cytokines and c-fos m-RNA expression in an isolated rat lung model. $J$ Clin Invest 1997; 99: 944-952.

37. Wrigge H, Zinserling J, Stuber F, et al. Effects of mechanical ventilation on release of cytokines into systemic circulation in patients with normal pulmonary function. Anesthesiology 2000; 93: 1413-1417.

38. Ricard JD, Dreyfuss D. Cytokines during ventilator-induced lung injury: a word of caution. Anesth Analg 2001; 93: $251-252$. 